\title{
Erratum to: Inhibition of Botulinum Neurotoxin A Toxic Action In Vivo by Synthetic Synaptosome- and Blocking Antibody-Binding Regions
}

\author{
M. Zouhair Atassi - Behzod Z. Dolimbek • \\ Lance E. Steward $\cdot$ K. Roger Aoki
}

Published online: 13 August 2010

(C) Springer Science+Business Media, LLC 2010

\section{Erratum to: Protein J (2010) 29:320-327 \\ DOI 10.1007/s10930-010-9255-3}

The Color figures are erroneously printed in grey scale of the article published in Volume 29 Issue 5.

The correct version of color figures are given below. Figures 2, 3, 4, 5, 6, 7, 8 .

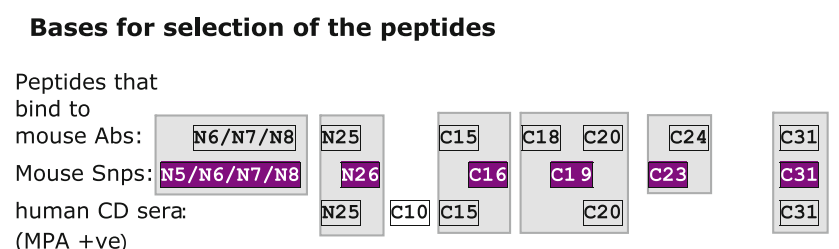

Fig. 2 Bases for selection of the peptides for in vivo inhibition studies. The figure shows schmetically the reasoning behind selection of these peptides for the in vivo studies. The selection was based on the ability of these peptides to bind blocking mouse anti-toxin Abs (7), blocking human anti-toxin Abs (19) and/or inhibition in vitro of the binding of labelled BoNT/A to mouse brain synaptosomes (38)

The online version of the original article can be found under doi:10.1007/s10930-010-9255-3.

M. Z. Atassi $(\bowtie) \cdot$ B. Z. Dolimbek

Department of Biochemistry and Molecular Biology,

Baylor College of Medicine, Houston, TX 77030, USA

e-mail: matassi@bcm.edu

\section{Z. Atassi}

Department of Immunology, Baylor College of Medicine,

Houston, TX 77030, USA

L. E. Steward · K. R. Aoki

Allergan, Inc., 2525 DuPont Drive, Irvine, CA 92612, USA

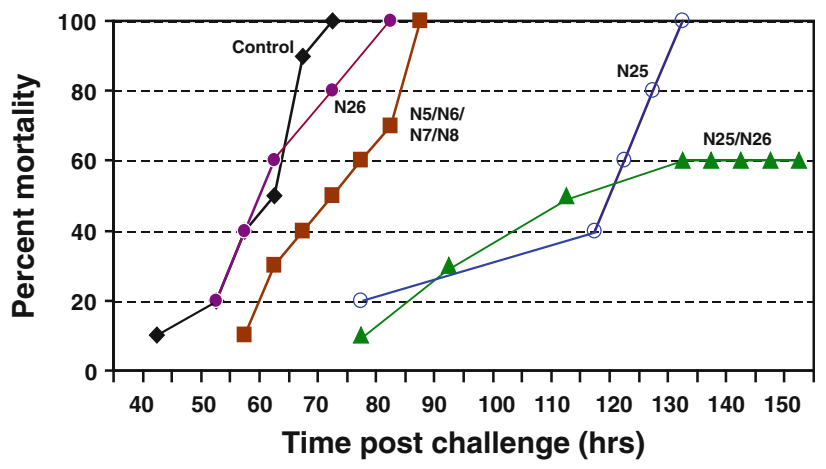

Fig. 3 Ability of the $\mathrm{H}_{\mathrm{N}}$ peptides $\mathrm{N} 5, \mathrm{~N} 6, \mathrm{~N} 7, \mathrm{~N} 8, \mathrm{~N} 25$ and $\mathrm{N} 26$ to interfere with the lethality of BoNT/A in mice. A given peptide (or mixture of peptides) was mixed with $1.05 \times \mathrm{LD}_{100}$ of active BoNT/A (i.e., $7.5 \mathrm{pg} /$ mouse $=5 \times 10^{-17} \mathrm{~mol}$ ) in $100 \mu \mathrm{L}$ of PBS containing $0.5 \% \mathrm{BSA}$, and the mixture was injected into $10 \mathrm{ICR}$ mice intravenously in the tail. The mice were observed three times a day for 6 days. When the peptide provided full protection, the mice survived the challenge. In the absence of protection no mice survived and the survival duration was similar to controls that received a $1.05 \times \mathrm{LD}_{100}$ of toxin alone without any peptide. In partial protection the survival time was increased

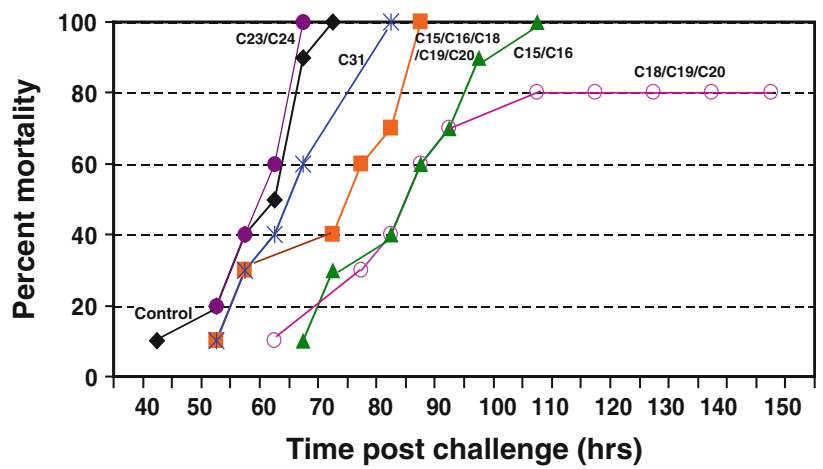

Fig. 4 Activity in vivo of the $\mathrm{H}_{\mathrm{C}}$ peptides to compete with the toxin and block its toxic action in mice. For experimental detail see Fig. 3 
Fig. 5 Images of BoNT/A with peptide regions of interest highlighted on the Connoly surface. The Hc domain is light blue, the $\mathrm{H}_{\mathrm{N}}$ domain is dark grey, and the LC is white. The solvent accessible region corresponding to $\mathrm{N} 25 / \mathrm{N} 26$ is red, C15/C16 is magenta, and C18/C19/C20 is orange. The three-dimensional coordinates are from the RCSB Protein Data Bank (PDB), accession code 3BTA (33)
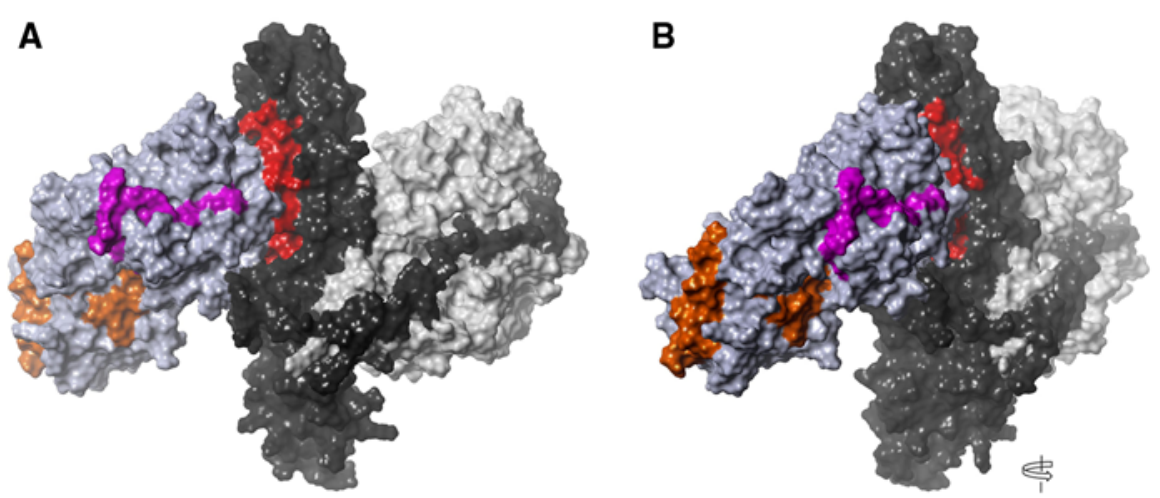

C

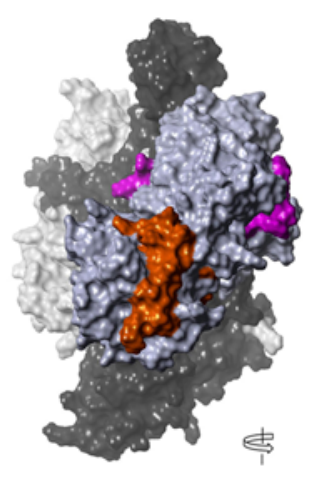

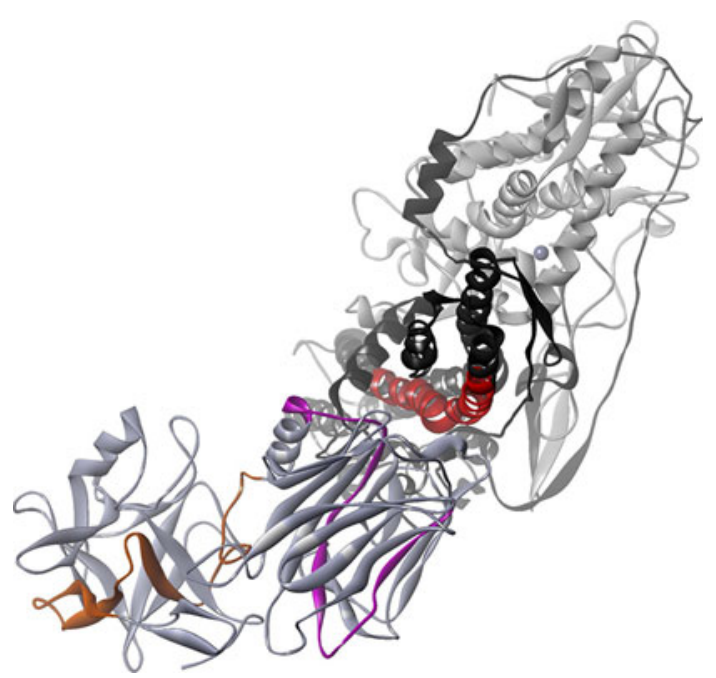

Fig. 6 Ribbon diagram of BoNT/A three-dimensional structure looking down the translocation domain to highlight the N25/N26 peptide region at the interface of the $\mathrm{H}_{\mathrm{N}}$ domain (dark grey) and the $\mathrm{HC}$ domain (light blue). The $\mathrm{C} 15 / \mathrm{C} 16$ region is magenta, and the $\mathrm{C} 18 / \mathrm{C} 19 / \mathrm{C} 20$ region is orange. The three-dimensional coordinates are from the RCSB Protein Data Bank (PDB), accession code 3BTA (33)

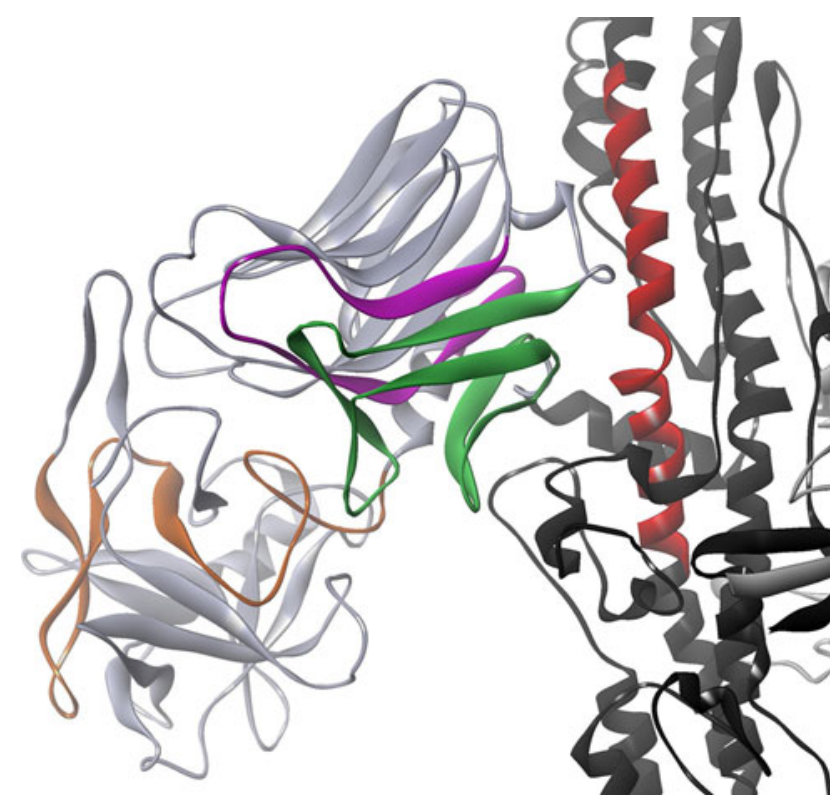

Fig. 7 Ribbon diagram of BoNT/A three-dimensional structure focused on the receptor binding domain ( $\mathrm{Hc}$, light blue) and portions of the translocation domain $\left(\mathrm{H}_{\mathrm{N}}\right.$, grey). The BoNT/A sequence corresponding to peptides $\mathrm{C} 15 / \mathrm{C} 16$ is magenta and immediately adjacent to that, the sequence that has been demonstrated to bind PIP (41) is shown in green. The three-dimensional coordinates are from the RCSB Protein Data Bank (PDB), accession code 3BTA (33) 

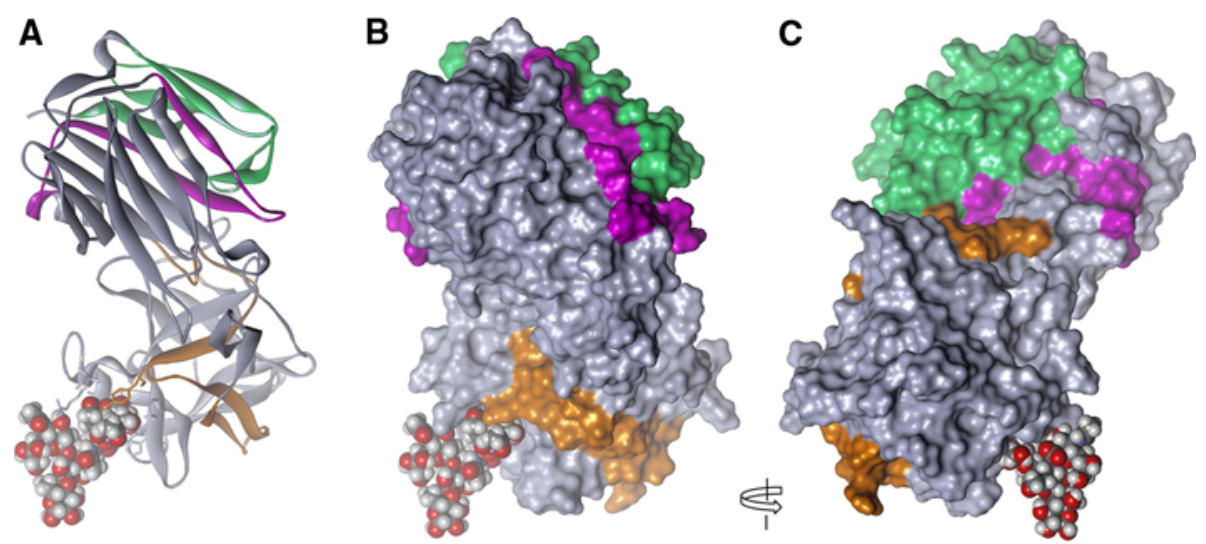

Fig. 8 Illustrations of the BoNT/A receptor binding domain (Hc) structure complexed with a GT1b analog. The sequence corresponding to peptides $\mathrm{C} 18 / \mathrm{C} 19 / \mathrm{C} 20$ in the Hcc are shown in orange. These peptide sequences comprise a portion of the $\beta$-trefoil that interacts with the dual receptors. A. Ribbon display with the residues interacting with the GT1b analog shown. Tyr1117 (orange) directly interacts with Sia5. B. Connolly surface display with the C18/C19/

C20 residues shown in orange and highlighting a potential groove for interaction with the protein receptor. C. Same Connolly surface display rotated ca. $180^{\circ}$. In all three images the residues corresponding to $\mathrm{C} 15 / \mathrm{C} 16$ are magenta and the proposed PIP binding site (41) is green. The three-dimensional coordinates are from the RCSB Protein Data Bank (PDB), accession code 2VU9 (52) 